\title{
Editorial
}

\section{International Perspectives on Worldviews in Education - Introduction to the Special Issue}

\author{
Laura Hirsto \\ University of Eastern Finland \\ Joensuu, Finland/ \\ University of Helsinki \\ Helsinki, Finland \\ Elina Kuusisto \\ University of Humanistic Studies \\ Utrecht, The Netherlands/ \\ University of Tallinn \\ Estonia, Tallinn \\ Martin Ubani \\ University of Eastern Finland \\ Joensuu, Finland
}

\begin{abstract}
The theme of this Special Issue is "International perspectives on worldviews in education". In literature, "worldviews" are often considered to be sets of beliefs and assumptions that describe reality (Koltko-Rivera, 2004). Worldviews are a topic that has been researched from various perspectives and through various theoretical constructs in the past. For instance, worldviews have been in the interest of theology and humanistic studies, but various researchers have also called for a better understanding of the worldview functions in the field of educational psychology (e.g. Rauste-von Wright, 1986; Hirsto, 2001a, 2001b; Koltko-Rivera, 2004;). In line with this, the special issue combines several perspectives from diverse contexts to the exploration of worldviews. In this introduction, these perspectives are combined by examining the meaningmaking and learning processes in relation to different conceptualisations in the case studies concerning worldview.
\end{abstract}

The articles in this special issue are based on an open call for papers that was connected to the EARLI" SIG 19 conference themed "Worldviews in creating

\footnotetext{
${ }^{1}$ European Association for Research on Learning and Instruction
} 
meaning and purpose for learning" held in 2018 at the University of Eastern Finland in Joensuu. This special issue is guest-edited by scholars representing EARLI Special Interest Group 19 Religions and Worldviews in Education. EARLI SIG 19 was established in 2003 under the name Religious and Spiritual Education to bring together researchers from various backgrounds, such as theology, religious studies, psychology, pedagogy, educational studies and philosophy. SIG 19 advocates for empirical and theoretical research that includes cognitive, social and emotional components.

This special issue consists of seven original and peer-reviewed articles as well as one opinion paper. First, Moran's conceptual paper discusses relationship between worldviews and life purposes by reviewing recent empirical findings of purpose studies around the world. Studies indicate that individualised and selffocused life goals are increasingly important to young people, also in traditionally collectivistic cultures. The results challenge educators, which is why Moran offers pedagogical tools to support the development of youth purpose.

In the second article, Häusler, Pirner, Scheunpflug, and Kröner review empirical studies on teachers' worldviews, which is a topic that has been mainly studied in the US, but European studies are lacking. The review demonstrates that religious beliefs are related to teaching, and especially in teaching science and religious education. Even though religious and worldview-related beliefs have a positive effect on teaching and coping, these beliefs can also interfere inappropriately in teachers' professionalism.

Hirsto's empirical study is the third article of the special issue. Hirsto investigates personal worldviews and their relation with the learning environment and certainty of career choices among Finnish theology students and teacher education students $(\mathrm{N}=211)$. Personal worldview perspectives with relation to the learning environment, referring to experienced positions of majority, minority or non-religious, are reflected in worldview commitment of the students. The study also indicates the power and ambivalence of personal worldviews on higher education students' learning and career choices.

The fourth article authored by Keränen-Pantsu and Heikkinen studies the pedagogical purposes for using narratives in religious and worldview education identified by Finnish primary school class teachers $(\mathrm{N}=6)$. This interview study finds narratives important in teaching to share knowledge, reflect on existential issues, develop ethical learning and promote a sense of community in the classroom. In worldview education, narratives seem to create safe spaces for reflecting on different convictions in pluralistic educational settings.

Similarly to the article by Keränen-Pantsu and Heikkinen, Cedillo, Kuusisto, and Tirri's investigate Finnish primary school class teachers $(\mathrm{N}=2)$ in the fifth article of the special issue. The article offers perspectives on education by examining gratitude, and how and why gratitude is expressed in first-grade classrooms. Analysis of videotaped lessons and stimulated recall interviews shows how the relationship between teacher and students induces the most gratitude and how students most often express their gratitude in concrete ways, such as by smiling or giving the teacher a hug. 
Sixth, de Groot, van den Berg, Leijgraaf, and ten Kate present an exploratory study on newcomer education in the Netherlands. The study illustrates how teachers navigate through and between diverse worldviews and belief systems of students in their attempts to create safe spaces and a sense of belonging, which the authors understand as an act of bonding. The article offers both conceptual and pedagogical ideas for educators and scholars investigating and providing education for refugees and migrants.

The seventh article of the special issue is written by Zhang, Kuusisto, and Tirri. The article compares implicit belief systems of students with different cultural and worldview affiliations, namely Chinese $(\mathrm{N}=705)$ and Finnish $(\mathrm{N}=495)$. The study shows how students from these diverse cultures have, on the one hand, have similar belief systems, and on the other hand they differ. For example, in both countries, intelligence is seen as malleable and more changeable than giftedness However, in China, students value and explain their academic achievement through effort, while Finnish students also attribute it to innate abilities, indicating that belief systems are associated with cultural and worldview underpinnings.

The last article of this special issue is an opinion paper where Alyssa Rockenbach provides an overview on her project on Interfaith Diversity Experiences and Attitudes Longitudinal Survey (IDEALS). With examples from research evidence as well as her personal life history, she draws an intriguing picture of how religious diversity experiences and worldview commitments are intertwined in the lives of minorities.

The contributions in the special issue show how worldviews are connected to people's motivation to learn, how worldviews guide people's life choices and future orientation as well as how worldviews and religions help people find meaning in life. Park (2010) also considers worldview perspectives as fundamental in the meaning-making system. Worldviews may affect people's choices explicitly or implicitly. In theoretical analysis of the meaning-making process, Park (2010) distinguishes between global meaning-making and situational meaning-making processes. According to Park (2010), global meaning-making refers to beliefs about self, the world and oneself in the world as well as goals and a subjective sense of meaning or purpose.

Worldview has also been conceptualised in other ways in earlier research. A general division between organised worldviews and personal worldviews has been suggested by van der Kooij, de Ruyter, and Miedema (2013). In their study, organised worldviews referred to more or less established systems with a group of believers, and personal worldviews to a person's view on life and humanity. Another distinction division could be made between the philosophical tradition and psychological tradition (e.g. Hirsto, 2001a, 2001b). According to philosophical tradition, worldview is considered to be general and collective, and according to the psychological tradition, worldview is seen as individualised. The philosophical perspective has been used to describe knowledge about the world. The term worldview, "Weltanschauung" in German, for example according to Häusler, Pirner, Scheunpflug, and Kröner in this Special Issue, denotes beliefs that offer holistic interpretations of the world 
and human life. In this sense, it does not necessarily refer to sacred or divine realities, but rather it can be regarded as an umbrella term covering religious and non-religious comprehensive beliefs.

In terms of the psychological conception of worldview, for example, Helve $(1987,1993)$ considered it according to the conative (or behavioural), cultural, cognitive, social and affective dimensions. This division, too, is concerned with the contents of outer reality, but its integral feature is also the way in which people see themselves as part of reality. Also, worldview differences regarding openness to religious diversity (e.g. Rockenbach, Mayhew, Morin, Crandall, \& Selznick 2015) or transformational learning (Mayhew, Hoggan, Rockenbach, \& Lo 2016) have been investigated. In the perspectives to worldview in the psychological tradition, it is thought that it is important to understand the function of worldview in human development and functioning (e.g. Rauste-von Wright, 1986; Hirsto, 2001a, 2001b). Worldview, in this respect, is constructed and reconstructed in continuous interaction with the physical and social environment. The physical and social environment can be conceived as a person's socialisation environment, which according to Bronfenbrenner (1979) should be understood as a systemic whole. This Special Issue brings together varying perspectives to worldview and personal worldview in varying international contexts in which the systemic socialisation environment is considered on various levels and in various cultural contexts.

According to Bronfenbrenner (1979), during a children's socialisation process, the socialisation environment expands from the one microsystem, usually formed by the childhood family, to various microsystems as the circles of life multiply through active interaction with various groups of people. Bronfenbrenner later developed his model towards the bioecological model, which centres on the individual and her/his characteristics and includes the temporal elements in the interaction (Bronfenbrenner, \& Morris, 1998). The temporal perspective of the socialisation environment is present in the papers of this Special Issue through the various educational contexts investigated through pupils and students' study contexts. In these systemic environments, people construct their personal worldviews. However, theoretically, the term "personal worldview" also has various interpretations. While van der Kooij et al. (2013) refer to it as a person's view on life and humanity, for Rauste-von Wright (1986) and Hirsto $(2001 \mathrm{a}, 2001 \mathrm{~b})$ it is more or less a process of interaction in which a person's beliefs about the physical and social reality are intertwined with the beliefs about oneself and values and higher level goals, and is related to person's psychophysiological state and cognitive-emotional competencies, skills and action strategies. On the basis of this fundamental interaction process, the person constructs situation-specific goals and intentions and chooses between alternative courses of action. These choices may be conscious or subconscious. Perspectives on this process can be found in Hirsto's article in this issue, as the university students' perspectives to the commitment to their worldviews seem to vary in different professional contexts, which may, at least partly be explained by the experiences in the learning environment in terms of the experience of representing part of minority or majority in the faculty. Also, Rockenbach's opinion paper in this Special Issue brings perspectives to the worldview issues 
from the perspectives of minorities. In Rockenbach's paper, worldview is conceived similarly to Häusler et al. in this issue, as she refers to use the term "worldview" intentionally instead of "religion" or "faith". For Rockenbach, worldview is a foundational outlook on life that helps people to make sense of the world.

As is considered in many papers in this special issue, "worldview" or "personal worldview" has a role in people's meaning-making processes, worldview is similarly seen to be related to life purposes. According to Moran's paper in this issue, individualised and self-focused life goals are increasingly important for young people also in traditionally collectivist cultures. In her article, Moran conceives the worldview as an implicit theory of how the world works, which frames how a person makes sense of experiences. In this sense, Moran's conception of worldview comes close to those conceptualisations of personal worldview (e.g. Rauste-von Wright, 1986; Hirsto, 2001a, 2012; Hirsto, in this issue), as according to her both worldviews and life purposes psychologically influence attention, action planning and sense of life coherence. She further suggests that instead of considering life purpose as an individual attribute, it should be considered a process of practice in which worldview and life purpose reciprocally compose each other to maintain self-regulation.

Some of the articles in this Special Issue approach worldview from the viewpoint of teachers on formal teaching and learning environments. For example, Häusler et al. in their review on the relation of teacher's religious or more broadly worldview beliefs, and professional beliefs is reflected. In this formal school context, Keränen-Pantsu and Heikkinen investigate teachers' perspectives of how they use narratives in the worldview education. These two papers take the perspective of an individual teacher. However, Keränen-Pantsu and Heikkinen connect the learning process more explicitly, on one hand, to wider systems of Bronfenbrenner's systemic model, such as exo- and macrosystems, to which pupils are not directly connected, but which regulate the pupils' immediate environments, and on the other hand, to the pedagogical interaction between teachers and pupils. Keränen-Pantsu and Heikkinen, in this issue, argue that teachers can resort to perspectives of the culturally formed stock of stories in their pedagogy from which teachers draw the narratives for which they have various uses in the worldview education to support pupils' learning and identity work. According to Keränen-Pantsu and Heikkinen, narratives may open up diverse ways of viewing the world and provide promising potential for worldview education.

Individuals' worldviews seem to have a role also in the way gratitude is enacted, according to Cedillo, Kuusisto, and Tirri in this issue. Cedillo et al. conceptualise worldview similarly to Häusler et al. and Rockenbach, as they refer to worldview as including views and beliefs about humanity, life, the world, social relationships and the underlying nature of reality. According to Cedillo et al. gratitude can be considered as a virtue when it is defined as a persistent disposition to act in a virtuous manner. Teacher and students induce gratitude the most, and the pupils express their gratitude most often in concrete ways such as by smiling. Cedillo et al. reflected on the gratitude in the Bronfenbrenner's (1979) microsystem of school in Finnish context, compared to 
Zhang, Kuusisto, and Tirri in this issue, who brought in a cultural comparison. The aim of cultural comparison required Zhang et al. to further conceptualise the relationship between worldview, cultural values and dimensions of cultures, as they compared Chinese and Finnish students' mindsets towards achievement. According the Zhang et al., there were differences in how students perceived and attributed academic achievement, which suggest that in Chinese culture, students emphasise effort more often than Finnish students, who again more often attribute learning success to ability. Also, Moran in this Special issue reflects on the division of cultures in terms of individualistic and collectivist cultures, and the relations with life purpose and shared worldviews. To overcome the difficulties of diversity of worldviews in educational contexts, de Groot, van den Berg, Leijgraaf, \& ten Kate suggest the use of bonding to navigate to navigate through the diversity. Their study offers insights of how teachers in newcomer classes and schools foster bonding, as it is understood as shared meaning-making and the co-creation of a shared cultural world.

The papers of this Special Issue bring various perspectives to the worldview into discussion. As in many papers, the idea of a contextualised approach to studying worldview themes seems important, and there is a nice collection of countries included in this Special Issue. Moran and Häusler et al. contribute with more general conceptual papers, and Cedillo et al. and Keränen-Pantsu and Heikkinen have acquired a Finnish data as well as Hirsto. Zhang et al. have comparative material from Finland and China, and de Groot et al. represent data from the Netherlands. Rockenbach's opinion paper relies on data that she and her research group have collected from the United States. All these contexts present pupils and students with different kinds of socialisation and learning environments in which they form their personal worldviews, and these environments can be investigated at Bronfenbrenner's (1979) various systemic levels, respecting the individual viewpoints and temporal dimensions represented by the bioecological model.

The variety of different uses of the worldview is evident, but there are similar tendencies and common undertones. However, as general classifications and divisions of various traditions of "worldview" can be found, there is still a need for further conceptualisation of worldview or personal worldview in the learning and teaching processes. This Special Issue is an attempt to collect the variety of worldview research together, also to provide perspectives for further research. As societies become more pluralistic and culturally varied through globalisation, it seems important to deepen our understanding and acquire deeper knowledge about effective worldview education and understanding of the functioning of personal worldviews in order to support teachers and facilitate meaningful and purposeful learning experiences for our next generations to come.

\section{Acknowledgments}

This special issue and the related EARLI SIG19-conference was supported partially by grants from The Board of Joensuu University Foundation and The Federation of Finnish Learned Societies (grant no 9992880-20181). 


\section{References}

Bronfenbrenner, U. (1979). The ecology of human development: Experiments by nature and design. Cambridge, M.A.: Harvard University Press.

Bronfenbrenner, U., \& Morris, P. A. (1998). The Ecology of Developmental Processes. In W. Damon (Series Ed.) \& R. M. Lerner (Vol. Ed.). The handbook of child psychology: Vol. 1. Theoretical models of human development 5th ed. (pp. 993-1028). New York: John Wiley \& Sons.

Helve, H. (1987). Nuorten maailmankuva. Seurantatutkimus pääkaupunkiseudun erään lähiön nuorista. Helsingin yliopiston uskontotieteen jaoston toimitteita 4. Helsinki: Yliopistopaino.

Helve, H. (1993). The world view of young people. Helsinki: Academia Scientiarum Fennica.

Hirsto, L. (2001a). Children in their learning environments: theoretical perspectives. Unit of Educational psychology. Research Reports 5/2001. University of Helsinki. Helsinki: Yliopistopaino. Retrieved from http://ethesis.helsinki.fi/julkaisut/kas/opett/vk/hirsto/

Hirsto, L. (2001b). Tytöt ja pojat oppimisympäristöissään. Psykologia, 36(5), 316-320.

Hirsto, L. (2012). Personal projects among students of theology. Motivational variations between different study phases. In Theo van der Zee, \& Terry Lovat (Eds.) New Perspectives on Spiritual and Religious Education (pp. 133-148). Münster: Waxmann Publishers.

Jacomijn C. van der Kooij, Doret J. de Ruyter, \& Siebren Miedema (2013) “Worldview": the Meaning of the Concept and the Impact on Religious Education, Religious Education. The official journal of the Religious Education Association, 108(2), 210-228. doi:10.1080/00344087.2013.767685

Koltko-Rivera, M. E. (2004). The psychology of worldviews. Review of General Psychology, 1(8), 3-58. doi:https:/ / doi-org.ezproxy.uef.fi:2443/10.1037/1089-2680.8.1.3

Mayhew, M. J., Hoggan, C., Rockenbach, A. N., \& Lo, M. A. (2016). The Association Between Worldview Climate Dimensions and College Students' Perceptions of Transformational Learning. The Journal of Higher Education, 87(5), 674-700. doi:10.1353/jhe.2016.0026

Park, C. L. (2010). Making sense of the meaning literature: An Integrative review of meaning making and its effects on adjustment to stressful life events. Psychological Bulletin, 136(2), 257-301.

http://dx.doi.org.ezproxy.uef.fi:2048/10.1037/a0018301

Rauste-von Wright, M. (1986). On personality and educational psychology. Human Development, 29, 328-340.

https:// doi-org.ezproxy.uef.fi:2443/10.1159/000273108

Rockenbach, A. N., Mayhew, M. J., \& Morin, S. \& Crandall, R. E. \& Selznick, B. (2015). Fostering the Pluralism Orientation of College Students through Interfaith Cocurricular Engagement. The Review of Higher Education, 39(1), 25-58. doi:10.1353/rhe.2015.0040 